\title{
COMPARTIMENTAÇÃO GEOAMBIENTAL COMO ETAPA METODOLÓGICA PARA DETECÇÃO E PROSPECÇÃO DE ÁREAS SUSCEPTÍVEIS À DESERTIFICAÇÃO (ASDS)
}

\author{
Flavio Rodrigues Do NASCIMENTO ${ }^{1}$ \\ Universidade Federal do Ceará \\ JULIANA FELIPE FARIAS ${ }^{2}$ \\ Universidade Federal do Rio Grande do Norte
}

\begin{abstract}
Resumo: A desertificação é resultante da conjugação de fatores climáticos somados às consequências de atividades humanas impactantes, desenvolvidas em ambientes áridos e semiáridos. As áreas desertificadas, com destaque para o Nordeste do Brasil, estão em expansão, comprometendo os recursos naturais em qualidade e quantidade, e o exercício de algumas atividades econômicas. Com base nessa discussão, é necessária a elaboração e a aplicação de medidas preventivas e corretivas para conter o avanço e o estabelecimento da desertificação. A partir dessa necessidade, o artigo apresentado traz uma proposta metodológica para a detecção e a prospecção de áreas susceptíveis a degradação, tendo como recorte de análise a bacia hidrográfica do Médio Jaguaribe, situada no estado do Ceará. Foi realizada a sua compartimentação, destacando os principais aspectos como: condicionantes ambientais e de uso/ocupação, espacializados em mapas temáticos. Os aspectos metodológicos foram ressaltados de maneira detalhada, para demonstrar que a proposta pode ser aplicada em outras áreas/setores. Como principais resultados foi possível destacar que a bacia teste está susceptível a desertificação, principalmente nas áreas dos sertões semiáridos, e que a metodologia proposta é eficaz na detecção de
\end{abstract}

\footnotetext{
${ }^{1}$ Professor do Departamento de Geografia da UFC e dos POSGEO UFC e UFF. Contato: flaviogeo@bol.com.br

${ }^{2}$ Professora do Departamento de Geografia da Universidade Federal do Rio Grande do Norte. Contato: julianafelipefarias@yahoo.com.br
} 
áreas susceptíveis a degradação, podendo ser utilizada em outros setores com adaptações realizadas ao objeto investigado.

Palavras-chave: Desertificação. Bacia hidrográfica. Análise geoambiental.

\section{GEOENVIRONMENTAL COMPARTMENTALIZATION AS METHODOLOGICAL STAGE FOR DETECTION AND PROSPECTING AREAS SUSCEPTIBLE TO DESERTIFICATION (ASDS)}

Abstract: The desertification is the result of a combination of climatic factors added the consequences of impacting human activities in arid and semi-arid developed environments. The areas of desertification, especially the northeast of Brazil, are expanding, compromising the natural resources in quality and quantity, and the exercise of certain economic activities. Based on this discussion, it is necessary the development and implementation of preventive and corrective measures to contain the spread and establishment of desertification. Based on this need, the article brings presented a methodology for detecting and prospecting areas susceptible to degradation, as an analytical cut the watershed of the Médio Jaguaribe, in the State of Ceará. The compartmentalization of the basin was carried out highlighting key aspects such as: environmental conditions and use/occupation, spatialized in thematic maps. The methodological aspects were highlighted in details, to demonstrate that the proposal can be applied to other areas/sectors. The main results can be noted that the basin test is susceptible to desertification, particularly in the areas of semi-arid backlands, and which the proposed method is effective in detecting areas susceptible to degradation and can be used in other sectors with adjustments made to the investigated object.

Keywords: Desertification. Watershed. Geo-environmental analysis.

\section{Introdução e a problemática da desertificação}

O termo desertificação foi assinalado por Abreuville em 1949, para indicar florestas equatoriais degradadas face ao mau uso dos recursos naturais. Vasconcelos Sobrinho, em 1976, foi um dos primeiros estudiosos a desenvolver estudos sobre o processo de desertificação no Brasil, e posteriormente diversos outros estudiosos trataram sobre o assunto, principalmente no Nordeste brasileiro. Na Eco-92, a problemática da desertificação foi definida como sendo: "Degradação da terra nas regiões áridas, semiáridas e subúmidas, resultantes de vários fatores, entre eles as variações climáticas e as atividades humanas", sendo este encontrado na Agenda 21 (Capítulo 12.2). Entre trabalhos brasileiros relevantes sobre a desertificação no Nordeste brasileiro, destacam-se: Nimer (1988), Brasil (2004) e Nascimento (2013), dentre outros.

Tal convenção definiu que a desertificação é "a degradação de terras em áreas áridas, semiáridas e subúmidas secas, resultante de vários fatores, incluindo variações climáticas e atividades humanas", sendo essa a definição mais aceita e usada entre os estudiosos do tema. Porém, é importante citar que são constatadas cerca de 59 conceituações sobre desertificação, onde todas têm como consenso que a degradação varia de ecozonas climáticas áridas a subúmidas secas (NASCIMENTO et al., 2007; NASCIMENTO, 2013). 
Por zonas áridas, semiáridas e subúmidas secas, a Convenção das Nações Unidas de Combate à Desertificação entende todas as áreas - com exceção das polares e subpolares - possuindo índice de aridez entre 0,05 e 0,65 ; tal índice é calculado correspondendo à relação entre precipitação pluviométrica e evapotranspiração potencial (BRASIL, 2004).

No Brasil o marco histórico de combate à desertificação ocorreu com a elaboração do Programa de Ação Nacional de Combate à Desertificação e Mitigação dos Efeitos da Seca, PAN-BRASIL. Estabelecendo políticas públicas e investimentos privados nas Áreas Susceptíveis a Desertificação (ASDs), propondo com isso promover o desenvolvimento sustentável.

No Nordeste brasileiro, o estado atual de conservação ou de degradação dos sistemas ambientais é reflexo do processo histórico de uso e ocupação da terra, portanto é contingência do atual modelo de produção e exploração do espaço. As áreas já fragilizadas pela semiaridez e/ou pelo uso inadequado dos recursos não se encontram com proteção devida. A deficiência de políticas de avaliação sobre as ASDs não permite que práticas sustentáveis de manejos sejam aderidas ao produtor agrícola, acarretando a decadência da produtividade agrícola, e acarreta em perdas consideráveis para a biodiversidade e para a população local. A rigor, nesta região existem áreas semiáridas e subúmidas secas, a par de sítios com susceptibilidade e ocorrência do processo de desertificação (Figura 1), tendo como estados mais afetados Piauí, Rio Grande do Norte, Paraíba, Pernambuco e o Ceará - este com 105 municípios com a presença do processo (BRASIL, 2004). 


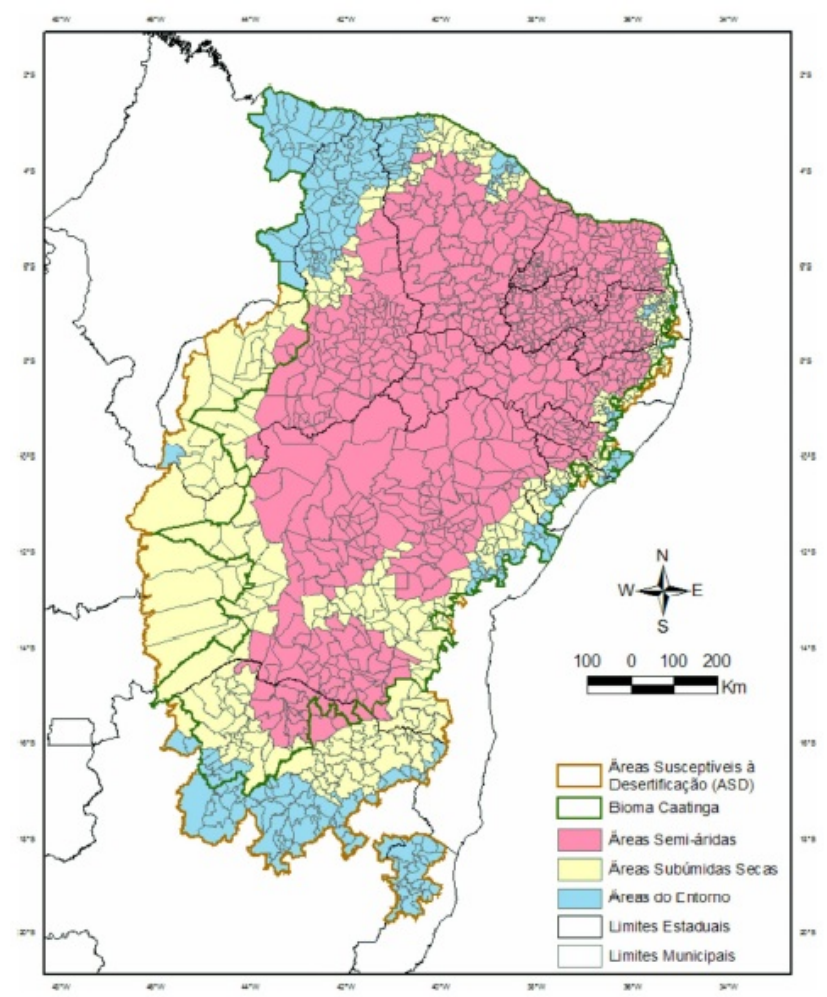

Figura 1: Mapa de áreas suscepctíveis à desertificação no Brasil Fonte: Brasil, 2004.

Várias causas contribuem para questão da desertificação no estado do Ceará, e uma delas é o estado ter a maior parte de seu território enquadrado no semiárido ( $92 \%$ de seu território), atrelado a uma história econômica de produção do espaço degradante, a partir de uso intensivo de recursos naturais - com destaque aos solos, águas e complexos vegetacionais do semiárido. Diante dessa perspectiva, o presente texto considera a dinâmica e a compartimentação geoambiental como etapa metodológica à detecção e prospecção de ASDs. Ademais, considera a Bacia Hidrográfica (doravante, $\mathrm{BH}$ ) enquanto unidade de estudo e planejamento ambiental. Para tanto, elegeu degradação ambiental e desertificação no semiárido cearense, Nordeste do Brasil, especialmente BH do Médio Jaguaribe como demonstração empírica-analítica. Aferida a compartimentação geoambiental com seu devido destaque metodológico, a próxima fase explicitou o esquema metodológico para Detecção e Prospecção de Áreas Susceptíveis à Desertificação (ASDs). 
A bacia teste está setorizada nos sertões semiáridos da depressão periférica do Médio curso do rio Jaguaribe, estado do Ceará, distando cerca de $200 \mathrm{~km}$ da capital Fortaleza (Figura 2).

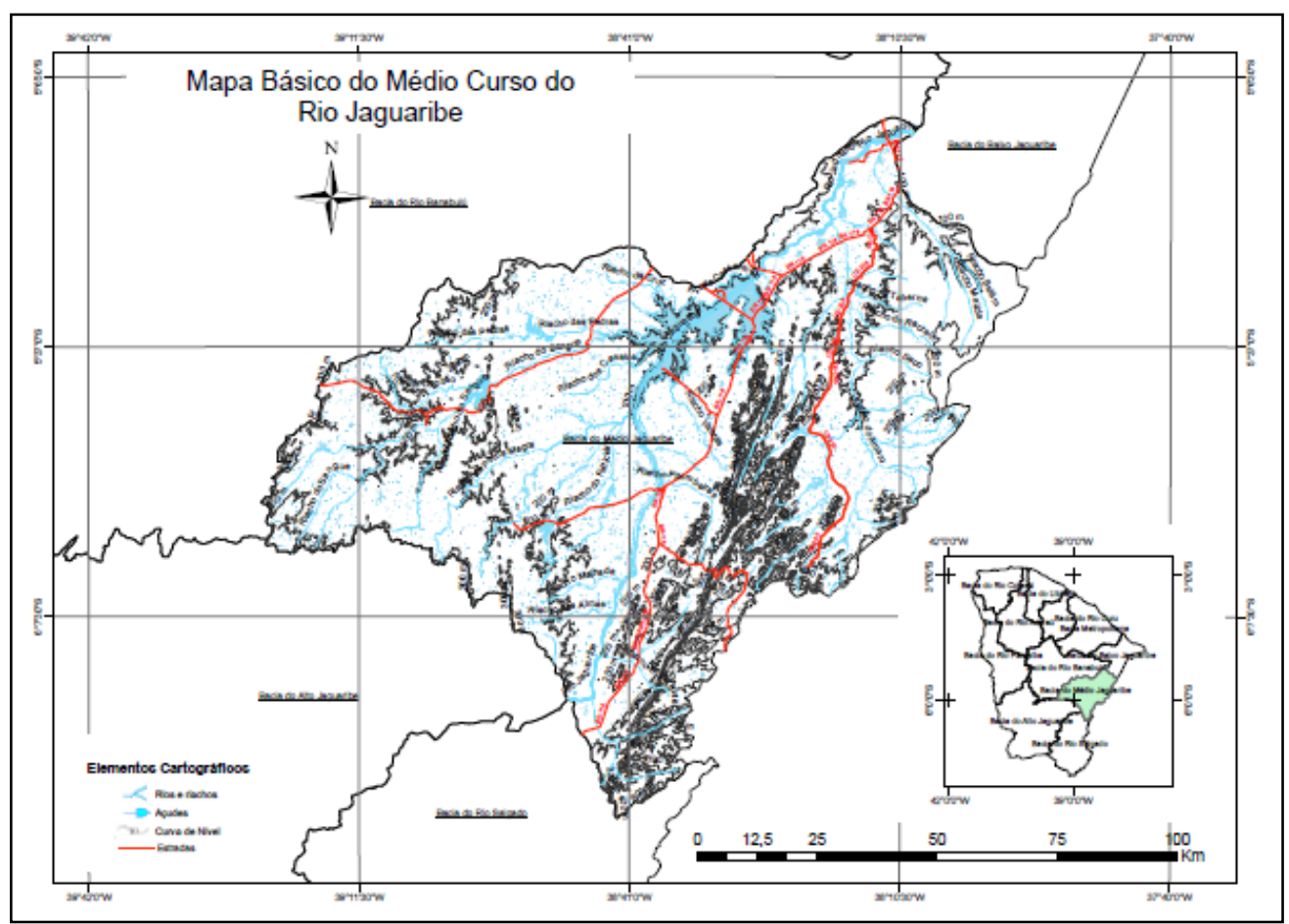

Figura 2: Localização da bacia de estudo Fonte: elaborado pelos autores.

Trata-se de uma bacia endorreica, haja vista dar passagem ao exutório Jaguaribe (Bacia do Jaguaribe composta pelas Sub-bacias Alto Jaguaribe, Salgado, Banabuiú, Baixo Jaguaribe e Médio Jaguaribe, é a maior do Ceará, com mais de $74 \mathrm{mil} \mathrm{km}{ }^{2}$ ou $50 \%$ do estado), em seu médio curso. Derivando-se da área territorial do total da Bacia do rio Jaguaribe, a bacia em foco representa aproximadamente 14,1\% do total, o que corresponde a $10.509 \mathrm{~km}^{2}$. De sudeste a nordeste, longitudinalmente, atingem distância máxima de $133,5 \mathrm{~km}$. De montante a jusante, drena áreas políticoadministrativas, total ou parcialmente, de 16 municípios, perfazendo um total populacional de 198.425 habitantes diretamente afetados.

Tal bacia engloba os municípios de Deputado Irapuan Ribeiro, Milhã, Solonópole, Jaguaretama, Jaguaribana, Pereiro, Ererê, Iracema, Potiretama, Alto Santo, São João de Jaguaribe e Jaguaribe, onde sua área de estudo corresponde a $10.509 \mathrm{~km}^{2}$. Sendo 
que agricultura, pecuária e pesca (com destaque ao açude Castanhão, segundo maior do Nordeste e o maior do Brasil para usos múltiplos) são os principais esteios econômico-produtivos da bacia. De um modo geral, a região é empobrecida economicamente, a par de pífios índices de IDH e PIB, com um peso significativo da economia pautado nas transferências governamentais. A pobreza chega a ser aviltante, especialmente sendo agravada nos momentos de secas, como o período atual de cinco anos de chuvas, com pelo menos $40 \%$ abaixo da média histórica (2011-2016).

O trabalho tem como pressuposto teórico-metodológico a análise geoambiental integrada, tomando-se como base uma concepção holística do ambiente, associada com fatores físicos e humanos que interagem mutuamente, destacando-se a geomorfologia como um meio metodológico para se alcançar a identificação e caracterização de cada compartimentação ambiental (Aires; Nascimento, 2007; Guerra, 2009), em termos de potencialidades e limitações em face da desertificação.

Assim, o estudo descarta a abordagem meramente setorial que enfatiza individualmente cada aspecto do ambiente - recobrimento vegetal, solos, clima, entre outros - para deter-se na análise integrada e nas correlações entre todos os componentes. Ademais, o presente capítulo elencou como área de estudo a Bacia do Médio Jaguaribe, localizada no estado do Ceará, em função de sua alta concentração de espaços desertificados e degradados ambientalmente.

\section{Estratégias metodológicas: compartimentação geoambiental e identificação da desertificação}

Foram consideradas algumas estratégias para avaliação do diagnóstico e compartimentação geoambiental da $\mathrm{BH}$ em questão, para verificar como esses resultados serviriam para a detecção de ASDs (Dregne, 1987), enfatizando o conhecimento integrado (SOUZA, 2000; NASCIMENTO, 2013). Quais sejam:

Bacia hidrográfica como unidade natural e do gerenciamento: calcada na questão dos recursos hídricos e da degradação ambiental: a partir de um contexto amplo de planejamento ambiental, permitirá a execução de trabalhos holísticos na abordagem sobre os recursos hídricos. Com a concepção de BH como unidade de manejo geoambiental, auxilia-se também na gestão ambiental, para administração do espaço em tarefa, com maior grau de eficiência para o gestor designado.

Análise dos atributos biofísicos: caracterização dos elementos geológicos, geomorfológicos, climáticos, hidrológicos ou dos recursos hídricos, solos e da cobertura vegetal. Seguida da identificação e da delimitação dos sistemas 
ambientais homogêneos - são resultantes do agrupamento de áreas dotadas de condições específicas quanto às relações mútuas entre os fatores do potencial ecológico (fatores abióticos) e aqueles da exploração biológica, compostos essencialmente, pelo mosaico de solos e pela cobertura vegetal. E, finalmente, é destacada a análise ecodinâmica - procedida com base em critérios de Tricart (1976 e 1977) anteriormente referidos, com as necessárias adaptações às características naturais da área. São consideradas como categorias de ambientes as seguintes: 1. Ambientes estáveis; 2. Ambientes de transição (intergrades) e 3. Ambientes fortemente instáveis.

Análise integrada: com base em sucessivos níveis de sínteses através de relações interdisciplinares, considerando os fatores do potencial ecológico (geologia + geomorfologia + climatologia + hidrologia), da exploração biológica (solos + cobertura vegetal + fauna) e das condições de ocupação e da exploração dos recursos naturais, foram estabelecidas, delimitadas e hierarquizadas as unidades espaciais homogêneas, configurando, cartograficamente, a compartimentação geoambiental em escala compatível com os objetivos, interesses e aplicabilidades práticas da pesquisa.

A análise dos atributos e da dinâmica natural que identifica os sistemas ambientais teve caráter globalizante e integrativo. Essa visão holísticosistêmica adotada faculta a compreensão das inter-relações e interdependências que conduzem à formação de combinações entre os atributos geoambientais. Desse modo, fica descartado o tratamento linear cartesiano que privilegia os estudos setoriais e distorce a visão sistêmica e de conjunto que configura a realidade regional.

Portanto, os compartimentos ambientais foram classificados e hierarquizados de acordo com suas dimensões e características de origem e de evolução. Visa-se, além disso, conhecer aspectos importantes dos processos evolutivos da região, suas potencialidades e limitações, para melhor avaliar a sua capacidade de suporte ao uso e ocupação (NASCIMENTO, 2013).

Considerando a diversidade interna de cada compartimento geoambiental, foram delimitadas as unidades elementares contidas em um mesmo sistema de relações, destacando-se, desta forma, as subunidades geoambientais. Sob esse aspecto, a concepção de paisagem assumiu significado para a delimitação hierárquica das subunidades, em função da exposição de padrões uniformes ou relativamente homogêneos.

$\mathrm{Na}$ preparação da legenda do mapa da compartimentação geoambiental foram selecionadas as características dos principais atributos geoambientais. 
Elas serviram de base para indicar condições favoráveis ou limitantes para o uso e a ocupação da bacia.

A identificação e a delimitação dos sistemas naturais, configuradas no mapa das unidades da compartimentação geoambiental, resultaram do agrupamento de áreas dotadas de condições específicas quanto às relações mútuas entre os fatores do potencial ecológico (fatores abióticos) e os da exploração biológica, compostos essencialmente pelo mosaico de solos e pela cobertura vegetal. Esse mapa, organizado através da interpretação das imagens de sensoriamento remoto do TM LANDSAT 5 e LANDSAT 7 ETM+, de imagens de radar, da análise do acervo cartográfico temático oriundo de levantamentos sistemáticos dos recursos naturais do Ceará, foi importante para o conhecimento e a avaliação da área de estudo. Ele forneceu os requisitos considerados imprescindíveis para definir a qualidade dos atributos naturais em termos de potencialidades e limitações, tendo em vista suas repercussões na qualidade ambiental.

A organização da legenda parte de uma hierarquia espacial taxonômica contida nas unidades inferiores propostas por Bertrand (1968), priorizandose, em função das ordens de grandeza, geossistemas e geofácies, isto é, compartimentos e subcompartimentos. É nessa perspectiva que os fatores geoambientais e os padrões de ocupação tendem a constituir dados instáveis onde se torna importante a acentuada variação temporo-espacial das paisagens. Assim, via de regra, os geossistemas são formados por paisagens diferentes e apenas os geofácies, como subunidades internas dos geossistemas, apresentam maior uniformidade.

Para delimitação dos geossistemas/geofácies da bacia, considerou-se a análise geomorfológica como elemento de importância fundamental. Segundo Souza (2000), os limites do relevo e as feições do modelado são mais facilmente identificados e passíveis de delimitação mais rigorosa e precisa. Deve-se reconhecer, além disso, que a compartimentação geomorfológica deriva da herança da evolução geoambiental, pelo menos tércio-quaternária. Como tal, cada compartimento tende a ter padrões de drenagem superficial, arranjamentos típicos do solos e características singulares quanto aos aspectos fitofisionômicos, e por consequência os padrões de ocupação são também influenciados.

Neste espectro, a bacia compartimentada, exibindo a espacialização de suas unidades geoambientais, facilita os trabalhos de detecção das áreas susceptíveis à desertificação. Como passo seguinte, mas que foge ao escopo deste trabalho, a prospecção e a identificação da desertificação de per si se 
daria por unidade geoambiental, podendo ser a unidade em tarefa $(\mathrm{BH})$ ainda ser setorizada em alto, médio e baixo cursos conforme suas condições topográficas (como exemplifica a Figura 3), fisiográficas e de hierarquia de drenagem. Deste modo, a identificação de ASDs poderia ser feita por unidade geoambiental ou por setor da $\mathrm{BH}$ suas respectivas unidades de paisagens. Deste modo, os trabalhos de sensores remotos, considerando o mapa básico (curvas de níveis, pontos contados etc.) e de uso/ocupação da terra, associados à ecodinâmica de Tricart (1977), correlacionada com categorias qualitativas de sustentabilidade e vulnerabilidade geoambiental de Souza (2000), se constituem como sequências metodológicas analíticas igualmente importantes.

A partir do levantamento bibliográfico e da visita ao local de estudo, foram realizados os mapas básico e de compartimentação ambiental. Para a confecção destes mapas, foi utilizado o programa SPRING versão 5.1.8 software livre desenvolvido pelo Instituto Nacional de Pesquisas Espaciais (INPE). Posteriormente esses dados foram migrados para o software ArcView GIS 10, que possui melhores opções de manipulação, editoração e consulta de mapas. Foram utilizadas as imagens com órbitas 216/64 e 217/64 do satélite LANDSAT 5 e mapas do Instituto de Pesquisa e Estratégia Econômica do Ceará para balizamento das informações.

A segunda etapa, igualmente importante, remete à classificação supervisionada de sensores remotos. Conforme Leite et al. (1993) e Nascimento (2013), a chave para essa fase é a identificação de áreas alteradas por degradação, que se deu por interpretação visual e automática das imagens de satélite. Deve ser destacada a interpretação do grau de reflectância das áreas e a redução da biomassa perceptível em áreas decapeadas, sendo observadas a forma e a dimensão das manchas. A verificação do mapa do índice de aridez (precipitação/evapotranspiração) desses autores guia o enquadramento das áreas degradadas, na isolinha de valor abaixo de 0,65. O índice de aridez favorece a caracterização da bacia em função dos fatores climáticos, considerando seus fatores sistêmicos, oferecendo indicações caras. de ordem biológica.

Os trabalhos de sensoriamento remoto devem ser usados simplificadamente nos SIG para determinação espacial da extensão da distribuição geográfica das áreas degradadas, relacionando as causas das ações humanas com as condições e os efeitos ambientais, conforme norteiam Rubio e Bochet (1998). 
Ademais, segundo o conceito oficial de desertificação, é através do índice de aridez (precipitação/evapotranspiração), que se pode enquadrar as áreas susceptíveis à desertificação em área hiperárida, semiárida, subúmida seca, desta forma: hiperáridas $<0,03$; áridas de $0,03-0,2$; semiáridas de 0,21 0,50; subúmidas secas de 0,51 - 0,65 e subúmidas >0,65 (Thornthwait, Mathier, 1955; UNEP, 1995; REDESERT, 1995; Nascimento, 2013). Neste sentido, Nascimento et al. (2007) indicam como roteiro metodológico associar os sistemas geoambientais $\mathrm{x}$ tipologias de solos $\mathrm{x}$ ecodinâmica $\mathrm{x}$ índice de aridez. Haja vista que este cruzamento de informações exibe como resultados as mudanças ambientais convergentes para estágios de degradação/desertificação dos recursos naturais.

\section{Diagnóstico geoambiental}

Os geoambientes são formados pela integração dos fatores clima, litologia, estrutura, relevo, vegetação, recursos hídricos e formas de uso/ocupação (BEROUTCHACHVILI; BERTRAND, 1978), interagindo de forma variada, configurando paisagens específicas para cada combinação, que são os aspectos visíveis para o sensoriamento remoto, ou seja, os geossistemas e geofácies/compartimentos geoambientais. A caracterização e a delimitação das unidades geossistêmicas correspondem às unidades geoambientais. A técnica de interpretação visual de imagens orbitais foi decisiva para compartimentação geoambiental.

Foi privilegiada a subcompartimentação geomorfológica, pois é a mais facilmente identificada, delimitada e interpretada, além de resultar da evolução dialética dos geoambientes, pelo menos tércio-quaternária, com cada compartimento denotando padrões próprios de drenagem superficial, tipos de solos, características peculiares de fitofisionomia. Consequentemente, os padrões de ocupação são também influenciados (SOUZA, 2000; SOUZA et al., 2005).

No que se refere às tipologias de uso/ocupação, inicialmente foi verificado o nível de aproveitamento dos recursos naturais e a qualidade ambiental, incluindo um inventário dos equipamentos urbanos e rurais, infraestrutura disponível, demografia e situação da população. Em seguida, foram conhecidas as diretrizes para avaliar a compatibilidade da ocupação, o uso dos recursos e os conflitos decorrentes. Foram analisadas as formas de uso e ocupação da terra, baseadas nos históricos de produção do espaço, nos principais aspectos socioeconômicos regionais nos produtos, agentes 
produtores do espaço e impactos ambientais resultantes das ações socioespaciais, conforme orienta Nascimento (2003). Ademais, completa o autor: "O levantamento dos aspectos econômicos e sociais foi realizado com o objetivo de observar como estes setores se apresentam em relação às condições ambientais dominantes" (NASCIMENTO, 2003, p. 21).

\section{Aspectos físico-geográficos e a desertificação}

Os sistemas ambientais foram classificados e hierarquizados de acordo com suas dimensões e conforme suas características de origem e de evolução. Objetivou-se, além disso, conhecer aspectos importantes dos processos evolutivos da região, suas potencialidades e limitações, para melhor avaliar a sua capacidade de suporte ao uso e ocupação.

A identificação e a delimitação dos sistemas geoambientais, configuradas no mapa das unidades da compartimentação homônima, resultaram do agrupamento de áreas dotadas de condições específicas quanto às relações mútuas entre os fatores do potencial ecológico (fatores abióticos) e os da exploração biológica, compostos essencialmente pelo mosaico de solos e pela cobertura vegetal.

O mapa da compartimentação geoambiental (Figura 3) agrega fatores do uso/ocupação e os biofísicos, ao tempo que foram selecionadas as características dos principais atributos ambientais. Elas serviram de base para indicar condições favoráveis ou limitantes para o uso e a ocupação da bacia frente às vicissitudes da semiaridez. 


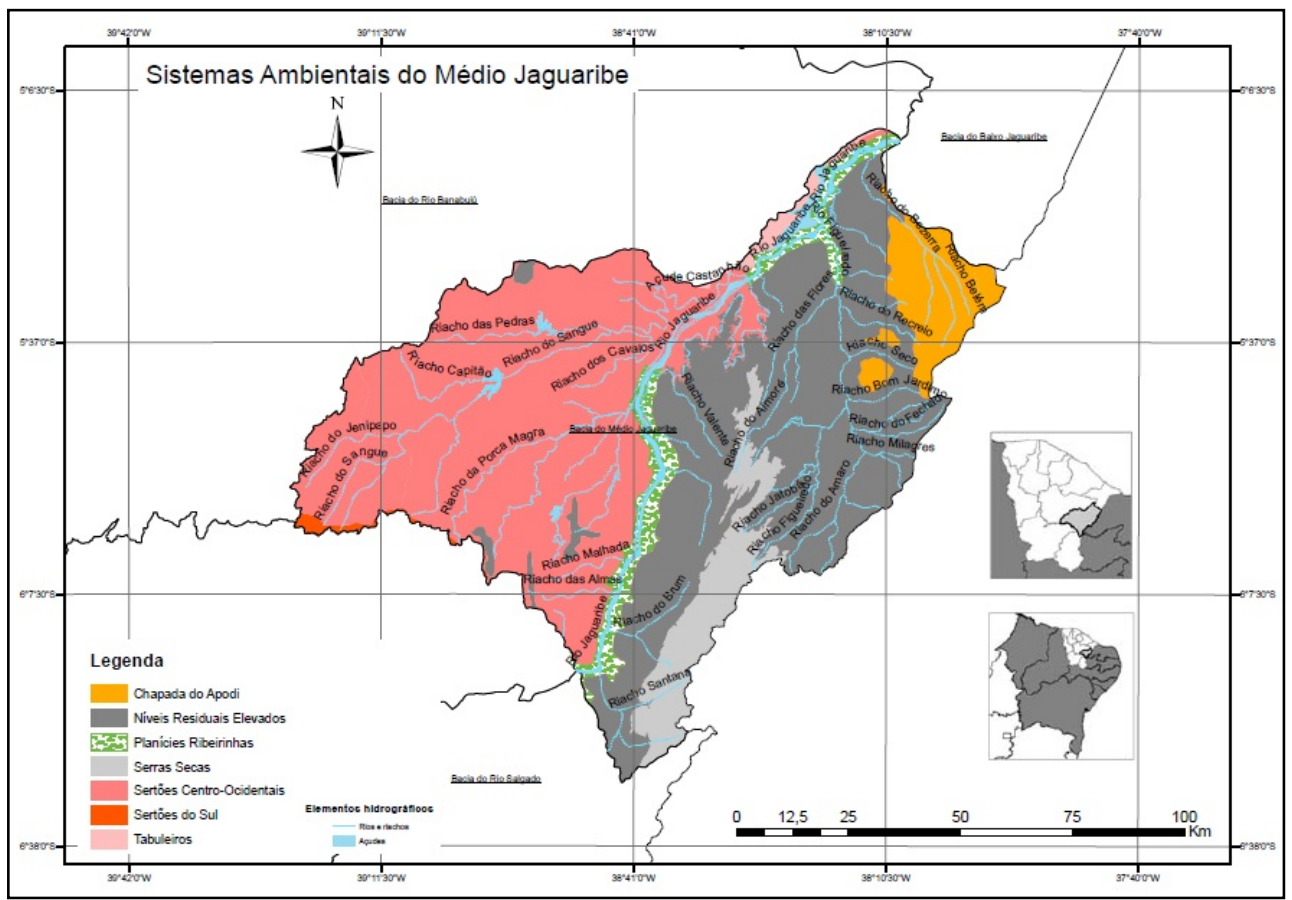

Figura 3: Mapa de compartimentação ambiental.

Fonte: elaborado pelos autores.

\section{Uso/ocupação da terra}

A demanda frente aos serviços naturais faz com que a transformação da natureza pelo trabalho ocorra em escala maximizada, pois a sociedade necessita que a produção não somente atenda à necessidade imediata da existência humana, mas também atenda aos interesses da textura social-global, alterando a relação proximal do homem com a natureza; haja vista que está se torna um mero recurso a ser explorado, sem observar a consequência do seu uso indevido (BERNARDES; FERREIRA, 2003).

A diversificação da paisagem depende da variedade de combinações entre os componentes geoambientais. As serras e as planícies são áreas mais densamente povoadas e de vida agrária mais intensa. Entretanto, a ocorrência de espaços diferenciados não chega, assim, a impor mudanças agudas quanto aos processos de utilização da terra. O que se nota, de modo indistinto, é a persistência de métodos rudimentares, desarmônicos com as condições de recursos naturais disponíveis. A homogeneidade do espaço estudado é assim vinculada à pobreza econômica e não propriamente às condições estritamente naturais. É certo, porém, que as limitações 
impostas pelas potencialidades ecológicas têm significado destacável para justificar a debilidade e a vulnerabilidade das atividades econômicas, muito dependentes da irregularidade pluviométrica do semiárido.

Sob o aspecto de uso/ocupação da terra, a Bacia do Médio Jaguaribe tem no setor primário da economia suporte fundamental, através de uma participação expressiva na formação da renda ou por representar a principal parcela do emprego regional. Esta situação, cabe salientar, vem se mantendo inalterada ao longo dos anos. Nesse particular, as limitações naturais têm papéis importantes para justificar um ritmo de crescimento que longe está de atingir o desejado.

A área dos sertões é, por excelência, o domínio do criatório extensivo, do agroextrativismo e da pequena lavoura de subsistência. Esse complexo representa o mais importante sistema de produção regional. Evidenciam-se mudanças apenas no tocante à combinação de fatores, pois ora há primazia da pecuária, ora da atividade agroextrativista e de subsistência. O perímetro irrigado da bacia se situa na Chapada do Apodi e em alguns setores ao entorno do açude Castanhão, dentre outros de menor expressão.

Neste contexto, as tipologias de uso/ocupação da terra se referem aos ativos ambientais - os recursos ambientais e humanos, e o modo de regulação da exploração pelos agentes produtores do espaço. Os valores da sociedade frente à natureza fazem com que esta seja sobre-explorada e seus serviços atendam ao interesse mediato do lucro de determinada parcela da sociedade. Estes fatores, associados a ambientes secos e em detrimento do mau uso dos recursos, fazem com que o processo de desertificação seja facilitado e acelerado. Toda transformação da natureza pela ação humana produz efeitos de degradação ambiental, e, dependendo do grau de alteração na natureza e da técnica utilizada, as degradações podem desencadear o processo de desertificação, impactando a diminuição da qualidade ambiental dos municípios.

As alterações no meio ambiente mantêm forte relação com as tipologias de uso/ocupação do solo e podem ser agrupadas, no caso do semiárido, de modo geral, em: ocupação urbana e industrial; usos múltiplos dos recursos hídricos e dos ambientes hidromórficos; recursos agrossocioeconômicos (NASCIMENTO, 2013). Tipologia essa que pode ser testada para a bacia em estudo, dadas as similaridades de bacias hidrográficas em terras secas no Ceará.

$\mathrm{Na}$ Bacia do Médio Jaguaribe a organização do espaço apresenta certas características geográficas e fisiográficas dotadas de similaridade, onde é possível perceber que a principal atividade no uso/ocupação da terra ocorra por meio da agropecuária. A rigor, são utilizados basicamente três sistemas de cultivo: lavouras de subsistência, agricultura irrigada e agricultura de sequeiro.

$\mathrm{Na}$ agricultura de subsistência, o processo de manejo do solo ocorre primeiramente através da retirada da vegetação, sequenciado pelas queimadas e manejo do solo. Isso para o cultivo de milho, feijão, mandioca, fava, melancia, algodão e outras, sempre consorciadas. Após alguns anos de cultivo, a terra é deixada em pousio, e 
posteriormente serve de local para pastagem do gado. Haja vista que em muitos casos ocorre consorciada a pecuária. Geralmente essas práticas fazem com que a área permaneça desnuda de vegetação e com os solos expostos à ação da erosão eólica período seco - e à erosão hídrica - período chuvoso. Ao longo deste ciclo, contudo, os solos estarão degradados, podendo em algumas situações ser irreversível, com consequente processo de desertificação se instalando.

Foi observado que cada unidade geoambiental possui um determinado padrão de atividades, em razão do sistema técnico utilizado, da história de ocupação e das potencialidades e limitações de uso dos recursos naturais. Deste modo, as tipologias de uso/ocupação da terra e seu mapa correlato estão baseados nas unidades geoambientais identificadas e mapeadas na Bacia Hidrográfica do Médio Jaguaribe, quais sejam: Chapada do Apodi; Níveis Residuais Elevados; Serras Secas; Sertões (Centro-Ocidental e do Sul); Tabuleiros Interiores.

$\mathrm{Na}$ Chapada do Apodi, a fruticultura é regra por meio da agroindústria/agricultura irrigada, principalmente com a produção de maçã, banana, limão, manga, mamão e melão. Toda produção agrícola voltada para a exportação, em detrimento do abastecimento do mercado interno.

Devido ao necessário capital para produção da agricultura especializada, há de se destacar a concentração da terra e a consequente expulsão do pequeno produtor desta região, em busca de terras de menor custo aquisitivo em face de sua sobrevivência. Outro uso/ocupação deste sistema ambiental ocorre com a apicultura, inclusive concorrendo como o maior produtor de mel entre os geoambientes de toda a $\mathrm{BH}$. Existem aproximadamente 260 toneladas de mel produzidos no ano de 2009, representando cerca de $9 \%$ de toda a produção estadual.

Neste geoambiente, ao longo das últimas três décadas foram registrados sérios conflitos pela posse da terra, evidenciando conflitos territoriais pelos usos dos recursos naturais entre grandes agroindustriais $\mathrm{x}$ pequenos produtores. Estes eram originalmente os donos das terras, mas sofreram processos de grilagem, expropriação e outros tipos de violência no âmbito deste conflito.

Este geoambiente é estrategicamente escolhido em função de sua infraestrutura hídrica e ótimas condições de solos (com cambissolos provenientes de calcários), sofrendo inclusive intervenção tecnológica, através de investimentos regulares e de elevado nível. Toda uma rede operacional é utilizada na produção da fruticultura que envolve assistência técnica e equipamentos de última geração - como pivô central, canais e adutoras drenando águas do açude Castanhão (o qual receberá as águas da transposição do rio São Francisco no Ceará), bem como assistência de crédito e de uma série de políticas públicas voltados ao seu desenvolvimento, em detrimento ao pequeno produtor rural. Ou seja, há todo um financiamento governamental na cadeia produtiva da agricultura irrigada.

Nos Níveis Residuais Elevados a agropecuária de subsistência ganha ênfase, principalmente com o bovino voltado para produção de leite e seus subprodutos. $\mathrm{Na}$ 
bacia como um todo, e nesta unidade geoambiental em particular, os produtores de laticínio são de pequeno porte, e alguns destes estão organizados em cooperativas, como a exemplo da Cooperativa de Lacticínios do Médio Jaguaribe. Outro ponto em evidência é a agricultura de sequeiro, que possui baixo rendimento e produtividade e as áreas são susceptíveis ao sistema incorporação-abandono, dado o esgotamento da capacidade produtiva dos solos pelo uso agropecuário intensivo associado ao baixo nível tecnológico e à pífia ou inexistente oferta de crédito ao produtor rural.

Grosso modo, a principal variação nos níveis produtivos é em função das práticas agrícolas inadequadas adotas neste sistema agroecossistema, por meio do uso indiscriminado dos recursos naturais, da retirada da vegetação, das queimadas, das técnicas adotadas no manejo do solo, do consorciamento com o gado, da compactação do solo, da erosão eólica e hídrica. Sem esquecer-se do ciclo destas práticas que levam à diminuição da fertilidade natural do solo e desencadeiam processos de degradação/desertificação.

$\mathrm{Na}$ Planície Ribeirinha, é desenvolvida a agropecuária de subsistência, principalmente com a policultura (milho, feijão e mandioca). Seu uso/ocupação se dá em função dos ambientes hidromórficos apresentarem condições edafológicas de alto potencial ao desenvolvimento da produção. Por outro lado, as margens de rios são Áreas de Preservação Permanente (APPs), e a ocupação com a substituição da vegetação ribeirinha pode desencadear conflitos ambientais e territoriais, entre atividades produtivas $\mathrm{x}$ preservação compulsória, bem como pela preservação compulsória $\mathrm{x}$ usos múltiplos dos recursos hídricos.

Também pode ocorrer consorciada aos produtos de subsistência a produção de frutas, com toda a produção voltada para atender, primeiramente, as necessidades da família, e posteriormente ao abastecimento do mercado local. Portanto, a agricultura de subsistência é realizada com baixos rendimentos e produtividade, como já fora apontado.

Já a pecuária ocorre nos âmbitos extensivo, semiextensivo e intensivo, porém se destaca a pecuária semiextensiva e intensiva, em que há preocupação com a melhora das condições do rebanho, a engorda e o corte do gado. Esta ocorre a partir do uso de pastagens cultivadas ou não, ambas susceptíveis às variações das chuvas.

Os canais fluviais (perenizados ou durante o período de chuvas) e os açudes são utilizados para dessedentação de animais, consumo de águas para utilidades domésticas, lavagens de currais e matadouro. É bom que se registre que todas as sedes municipais e distritos possuem água encanada - embora a cobertura não seja de $100 \%$ dos domicílios. Seja pelo projeto São José, pela Autarquia Municipal de Água e Saneamento (SAAE) ou pela Companhia de Águas e Esgotos do Ceará (CAGECE).

Sendo assim, os açudes públicos são as principais fontes de abastecimento de água e têm por meio do SAAE e CAGECE diversos pontos de capacitação espalhados pelos equipamentos hídricos que compõem a bacia. Por outro lado, o projeto São José trabalha no sistema de poços, adutores, caixas d'água e cisternas de placas para o 
provimento de água para o abastecimento doméstico nas menores comunidades rurais.

É comum haver matadouros localizados próximo aos rios e açudes, contribuindo assim para degradação da qualidade das águas nos corpos hídricos. $\mathrm{O}$ ambiente hidromórfico é utilizável também para o transporte fluvial, a pesca e a piscicultura.

Nas Serras Secas, a visibilidade ocorre com a pecuária extensiva, semiextensiva e intensiva, entretanto a ênfase é da pecuária extensiva representada pela bovinocultura, ovinocultura e caprinocultura, consorciada à agricultura de subsistência destinada ao abastecimento do comércio local, desenvolvidas em terrenos com baixa fertilidade de solo, pedregoso e com condicionantes edafoclimáticos limitantes. A produção pecuarista ocorre em conjunto com a agrícola, sendo produzidos feijão, milho, algodão, entre outros. Devido às condições naturais serem limitantes, o principal problema deste sistema ambiental é a baixa produtividade do solo. Esta limitação, atrelada às restrições topográficas e às declividades acentuadas, originam processos de solifluxão e erosão profunda, ocasionando ulcerações nas paisagens serranas típicas de áreas desertificadas.

Nos Sertões (Sertões Centro-Ocidentais e Sertões do Sul) o destaque é da agropecuária de subsistência e comercial, com unidades produtivas de tamanhos pequeno a médio. Correspondem ao geoambiente predominante na bacia, com uso comum do solo por meio da agricultura, seguida da pecuária, todas de subsistência e usualmente consorciadas. Quando a pecuária não é de subsistência, ela serve menos ao corte e mais ao leite.

A agricultura de subsistência é realizada com o predomínio da pequena produção, porém se evidencia uma ampla diversidade de produtos, como milho, feijão, mandioca, batata-doce, algodão, mamona. Com a pecuária voltada para o leite, este é beneficiado artesanalmente para a fabricação de queijos, manteigas e outros subprodutos. Os animais de corte têm suas peças comercializadas em mercados locais e sub-regionais, servindo basicamente ao consumo das comunidades residentes nos municípios que compõem a bacia em estudo. O couro, como subproduto, é muito apreciado nas poucas indústrias de transformação existentes, especialmente para fabricação de calçados e bolsas.

Nos Tabuleiros Interiores a ênfase na relação uso/ocupação da terra ocorre através da atividade da cajucultura e a ocupação urbana planejada, onde ganha destaque a cidade de Nova Jaguaribara.

$\mathrm{Na}$ cajucultura o ecossistema é monoespecífico, sendo o caju beneficiado para a fabricação de doce, polpa e cajuína - bebida típica nordestina; quanto ao fruto, ou seja, a castanha tem parte da produção vendida no comércio local e outra para agroindústrias de castanhas localizadas na Região Metropolitana de Fortaleza.

O nível técnico utilizado para a produção é baixo, com poucos investimentos. No geral, os cuidados se dão com o espaçamento dos indivíduos e podas das árvores. A cujucultura na bacia não é irrigada, sendo as plantações desenvolvidas 
estrategicamente em terrenos permoporosos dos tabuleiros e sobargissolos vermelhoamarelos, quando o acesso ao lençol freático pela função biológica das raízes na busca da água é relativamente facilitado ao se comparar com os solos comumente raros e pedregosos dos sertões. A Figura 4 espacializa as tipologias de uso/ocupação discutidas acima na bacia teste.

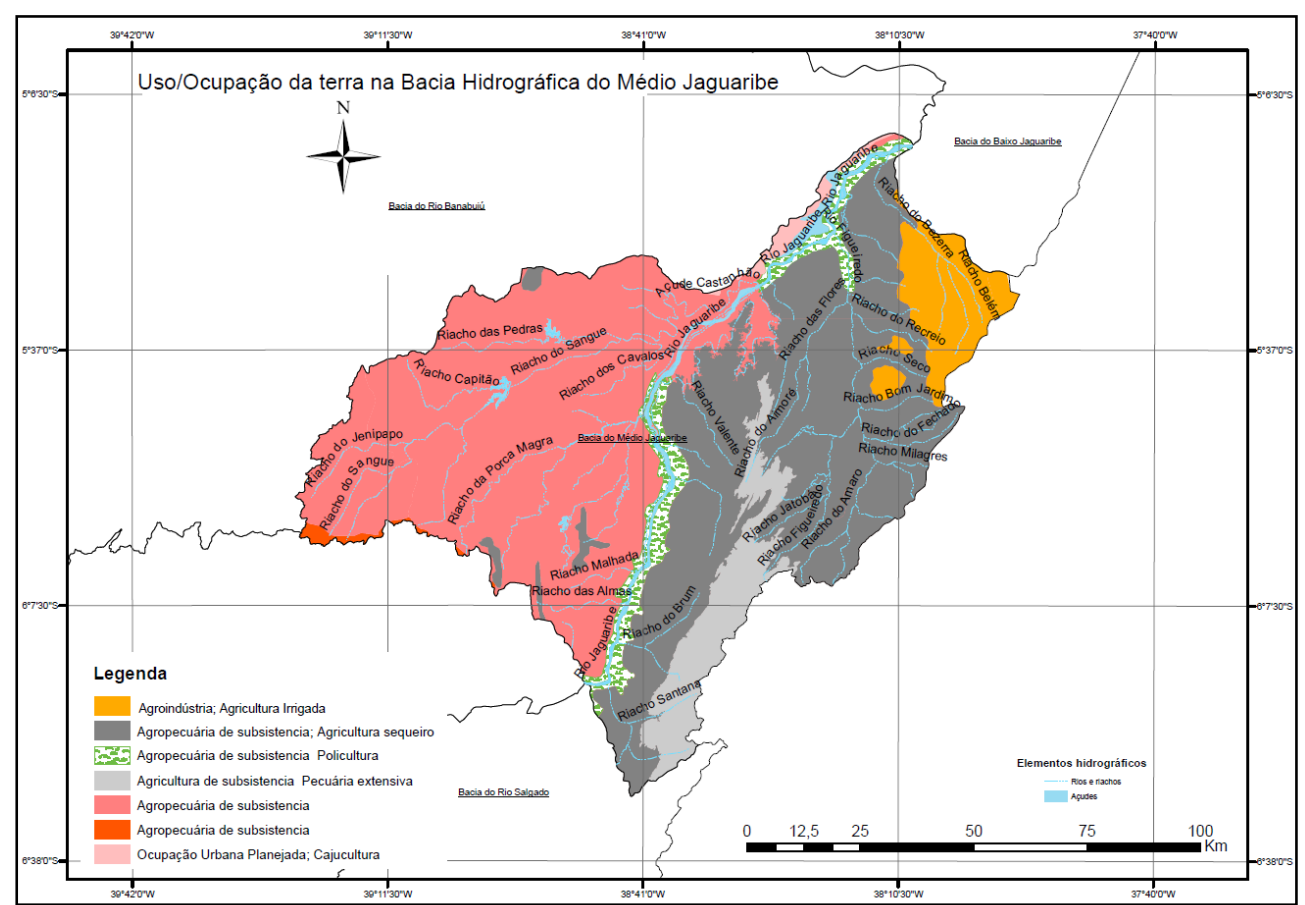

Figura 4: Mapa uso/ocupação da terra na Bacia Hidrográfica do Médio Jaguaribe Fonte: elaborado pelos autores.

\section{Considerações finais}

$\mathrm{O}$ artigo mostrou uma primeira aproximação metodológica para detecção e prospecção de Áreas Susceptíveis à Desertificação (ASDs). Para o momento, foi considerada a Bacia Hidrográfica como unidade de estudo e análise (no caso a do Médio Jaguaribe, no semiárido nordestino, Ceará) a partir de uma proposta de compartimentação geoambiental da mesma, com a efetivação de mapeamentos. A rigor, os mapas elaborados foram os seguintes e trataram de temas específicos:

Mapa básico - Onde foram plotados os elementos cartográficos (com topografia, curva de níveis, rodovias e sedes municipais e principais localidades). Este mapa é 
fundamental para delimitação da bacia e foi o que serviu de base para os demais mapas elaborados.

Mapa de compartimentação geoambiental - Igualmente importante, deriva do primeiro e mostra a bacia dividida em $\mathrm{x}$ unidades de paisagens, a partir das quais podem ser subdivididas $\mathrm{x}$ unidades geoambientais, enquanto unidades hierquicamente menores, as quais estão expostas nos quadros 1 e 2 . As unidades maiores mapeadas foram: Chapada do Apodi, Níveis Residuais Elevados, Planície Ribeirinha, Serras Secas, Sertões (Sertões Centro-Ocidentais e Sertões do Sul) e Tabuleiros Interiores.

Mapa de tipologias de uso/ocupação da terra - Mapa temático fundamental para o desenvolvimento e a complementação metodológica. Neste mapa, para cada compartimento geoambiental foram identificadas as principais atividades produtivas e as alterações ambientais em face das mudanças emergentes nos arranjos de uso/ocupação identificados.

As tipologias identificadas e discutidas por unidades geoambientais, e no contexto da problemática das ASDs, foram:

- Agroindústria e agricultura irrigada na Chapada do Apodi.

- Agropecuária de subsistência, agricultura de sequeiro nos níveis residuais elevados.

- Agropecuária de subsistência com policultura nos vales fluviais, sobretudo dos rios principais.

- Agricultura de subsistência com agropecuária extensiva nas serras secas.

- Agropecuária de subsistência sertões centro-ocidentais e nos de centrosul.

- Nos tabuleiros interiores há ocupação urbana planejada com a cidade de Nova Jaguaribara e cajucultura.

Determinismos à parte, convém registrar que a associação à análise do uso/ocupação por unidades de paisagens, além de manter o rigor da proposta metodológica, ainda destaca as potencialidades e limitações de uso dos recursos naturais em termos de influências biofísicas em relação às atividades produtivas.

Com as informações dispostas por este mapa, foi gerado um banco de dados. Como segunda etapa metodológica, procurar-se-á sobrepor estes resultados às imagens analógicas em transparência de sensores remotos, associados às aerofotografias. Como técnica, será produzida uma classificação supervisionada mostrando matizes que representam os diversos estados de conservação da vegetação e exposição dos solos, e que mostram consequências em termos de degradação/desertificação, para, enfim, se desenvolver o mapeamento de ASDs.

Assim se dariam bases qualitativas e quantitativas para detecção e prospecção tendo como etapa fundamental e inicial a identificação e a compartimentação geoambiental, a qual pode ser ratificada ao se considerar a bacia hidrográfica como 
unidade de estudo. Neste mister, Nascimento (2011) coloca que a bacia, considerada como unidade de pesquisa e planejamento para o escopo de pesquisa a partir do temário deste texto, apresenta vantagens em sua concepção também como unidade de intervenção política, eis que:

Facilita estudos sobre os recursos naturais em suas áreas de drenagem, por se comportar como unidade natural indissociável, facilitando, assim, a análise da degradação ambiental tomando-se por base sistemas fluviais;

Em seu âmbito, é possível subsidiar o desenvolvimento de parcerias e resolução de conflitos. Estimula e permite a participação popular, democraticamente, com relação ao poder público, organizações não governamentais (ONGs) e entidades privadas;

No que descentraliza os trabalhos de conservação e proteção ambiental, estimulando as integrações comunitária e institucional;

Possibilita uma forma racional de organização de banco de dados, além de garantir opções para o uso dos mananciais e de seus recursos naturais;

Evidencia o estado de degradação ambiental pela eutrofização, bem como pelo assoreamento dos corpos hídricos;

Apresenta um arcabouço jurídico-ambiental bem consubstanciado para o combate à degradação ambiental/desertificação, nas Áreas Susceptíveis à Desertificação (ASDs).

Por fim, diz-se que toda bacia está susceptível à desertificação, especialmente nas áreas dos sertões semiáridos. E, muito embora este fenômeno ocorra em processos areolares, os vales com seus processos lineares, também, se veem ameaçados em função do avanço da degradação/desertificação.

Entrementes, dadas as bases geoambientais da bacia em estudo, enquanto unidade explicativo-analítica da questão aqui tratada, a verificação pormenorizada das ASDs está posta na agenda de atividades dos pesquisadores que assinam este trabalho, enquanto continuidade de uma pesquisa mais aprofundada.

\section{Referências}

AIRES, R.; NASCIMENTO, F. (2007) Condições morfoestruturais das microbacias cearenses de Muquém, Riacho das Pedras e Neblina. In: AMORA, Zenilde B.; CARLEIAL, Adelita et al. (Orgs.). Cenários geográficos: reflexões e enfoques. Fortaleza: Eduece, p. 271-284.

BERNARDES, J. A.; FERREIRA, F. P. M. (2003) Sociedade e natureza. In: CUNHA, S. B. da; GUERRA, A. J. T. A questão ambiental: diferentes abordagens. Rio de Janeiro: Bertrand Brasil, p. 17-42.

BEROUTCHACHVILI, N.; BERTRAND, G. (1978) Le Geósysteme ou Systém Territoriel Naturel. Revue Geógraphic de Pyrinées e Sud-Ouest, v. 49. 
BERTRAND, G. (1968) Paysage et Géographie Physique Global. Esquisse Méthodologique. Revue Géographique dês Pyrenées et du Sud Ouest. Toulouse, France. 39(3), p. 249-272.

BRASIL. Ministério do Meio Ambiente - MMA (2004) Programa de Ação Nacional de Combate à Desertificação e Mitigação dos Efeitos da Seca, PAN-BRASIL. Edição Comemorativa dos 10 anos da Convenção das Nações Unidades de Combate à Desertificação e Mitigação dos Efeitos da Seca - CCD. Brasília: MMA, 225 p.

DREGNE, H. E. (1987) Envergadura y difusión del processo de desertificación. In: Programa de las Naciones Unidas para el Médio Ambiente (PNUMA): Comisión de la URSS de los Asuntos de PNUMA. Colonización de los territórios áridos y lucha contra la desertificatión: enfoque integral. Moscu: Centro de los Proyectos Internacionales - GKNT, p. 10-17 (Capitulo I).

GUERRA, D. F. A. (2009) Problemática da desertificação nos sertões do Médio Jaguaribe: o contexto do município de Jaguaribe - CE (Dissertação de Mestrado). UECE: Fortaleza, p. 10-23.

LEITE, F. R.; SOARES, A. L.; MARTINS, M. L. R. (1993) Áreas degradadas susceptíveis aos processos de desertificação no estado do Ceará - $2^{\mathrm{a}}$ Aproximação. In: Anais do VII Simpósio Brasileiro de Sensoriamento Remoto. Curitiba - PR, p. 156-162.

NASCIMENTO, Flávio R. (2003) Recursos naturais e desenvolvimento sustentável: subsídios ao manejo geoambiental na sub-bacia do Baixo Pacoti - Ceará. (Dissertação de Mestrado). Fortaleza - CE.

et al. (2007) Desertificação em bacias hidrográficas semiáridas no Nordeste brasileiro - Estado do Ceará. In: BEZERRA, A. et al. (Orgs.). Itinerários geográficos. Niterói: POsGEO UFF, p. 281-310.

. (2011) Categorização de usos múltiplos dos recursos hídricos e problemas ambientais. Revista da ANPEGE, v. 7, p. 81-97.

. (2013) O fenômeno da desertificação. Cegraf: Goiânia. 270 p.

REDESERT - Rede de Informações e Documentação em Desertificação (1995). $O$ que é desertificação.. Disponível em: <http://gov.br/port/redesert/desertmu.html>. Acessado em: 8/5/2015.

NIMER, Edmond. (1988) Desertificação: mito ou realidade. Rev. Brasileira de Geografia. IBGE: Rio de Janeiro. V 50. N. 1. P. 7-39.

RUBIO, J. L.; BOCHET, E. (1998) Desertification indicators an diagnosis criteria for desertification risk assessment In: Europe. Journal of Arid Environments (JAE): International Symposium and Workshop - "Combating Desertification: connecting cience with Community Action". Vol. 39, article n. ae 980402. Academic Press Limited. Tucson, Arizona: USA, p. 113-120.

SOUZA, Marcos J. N. (2000) Bases geoambientais e esboço do zoneamento geoambiental do estado do Ceará. In: LIMA, Luiz Cruz. Compartimentação territorial e gestão regional do Ceará. Fortaleza: FUNCEME, p. 104. 
et al.(2005) Zoneamento ecológico-econômico das áreas de influência do reservatório da barragem Castanhão. Tomo 3: prognóstico: cenários tendenciais e desejáveis. DNOCS-UFC/CETREDE,197 p. TRICART, J. (1976) A geomorfologia dos estudos integrados do Meio Natural. Bol. Geográficos, n. 251, Rio de Janeiro. . (1977) Ecodinâmica. IBGE, Rio de Janeiro.

THORNTHWAIT, C. W.; MATHIER, J. R. (1995). The Water Balance. Publication in Climatology, v. 8, n. 1, Laboratory of Climatology, Senterton, New Jersey. UNITED NATIONS ENVIRONMENT PROGRAMME (UNEP) (1995) News of Interest. In: Desertification Control Bulletin: A Bulletin of World Events. The Control of Desertification, Restoration of Degraded Lands an Reforestation. Number 27, p. 93-96.

Data de submissão: 07/12/2015.

Data de aceite: 20/10/2016. 